\section{A history of the brain: From stone age surgery to modern neuroscience}

Autor: Andrew P. Wickens, PhD

Editorial: Psychology Press, Taylor \& Francis Group

Primera edición 2015, London, United Kingdom ISBN: 978-1-84872-365-8

Andy Wickens, profesor titular de psicología y neurociencia en la University of Central Lancashire, Reino Unido, nos entrega este motivador y detallado libro que pretende, con gran éxito, exponer el devenir histórico del estudio del cerebro, tanto en lo que respecta a su comprensión filosófica como fisiológica. Y, además, respecto a cómo esta última se empotra sobre la primera, dejando entrever el bosquejo de los supuestos epistemológicos que asientan nuestra actual comprensión en neurología, psiquiatría y psicología.

Los primeros dos capítulos se hacen cargo de exponer de qué manera las personas de la edad de piedra y de civilizaciones que brillaron en las postrimerías de la prehistoria, se explicaban el origen y la mecánica subyacente de la conducta y de la actividad mental. Qué rol le atribuían al cerebro y mediante qué métodos llegaban a sus conclusiones, ya fuesen éstos más cercanos a la especulación o la experiencia empírica. Y, posteriormente, el largo y sinuoso camino hacia las experiencias de Galeno y su legado, ya en el siglo II d. C.

Del tercer capítulo al sexto, se presentan eventos relevantes ocurridos entre la tardía Edad Antigua hasta el Siglo de las Luces, período en el cual tal vez ocurrieron la mayor parte de las transformaciones filosóficas en la comprensión del sistema nervioso: por una parte, los aportes en neuroanatomía de Mondino de Luzzi, Leonardo Da Vinci, Andreas Vesalius y el asentamiento de la teoría celular. Por otra parte, la filosofía metafísica de René Descartes, las contribuciones a la fisiología de Thomas Willis y Albrecht von Haller $y$, así, dando un paso más firme hacia el quehacer científico, la incorporación del descubrimiento de la electricidad en los animales, el uso del galvanómetro y el descubrimiento de los potenciales de acción. Finalmente, el ascenso y la caída de la frenología, disciplina que, si bien incurrió en numerosos errores metodológicos, instauró la idea de que las funciones mentales podían tener una localización cerebral.
Del séptimo al noveno capítulo se exponen descubrimientos que fueron críticos tanto para el desarrollo de la biología celular como de la neurobiología y neurohistología. Entre ellos, los avances en microscopía, el desarrollo de técnicas de tinción, y la construcción de una comprensión más detallada de la arquitectura del cerebro, para lo cual fueron esenciales los trabajos de Jan Purkinje, Robert Remak, Camillo Golgi y Santiago Ramón y Cajal, entre otros. Subsecuentemente, se exponen los hallazgos claves en el estudio de los reflejos y las conexiones sensitivo-motoras, aludiendo a investigaciones llevadas a cabo por Marshall Hall, Ivan Sechenov, Charles Sherrington, Ivan Pavlov, Karl Lashley y Donald Hebb, entre otros. Finalmente, se esboza un episodio que actualmente es etiquetado como el nacimiento de la neuropsicología moderna: las experiencias clínicas de Jean-Baptiste Bouillaud, Ernest Aubertin y Paul Broca en afasiología y, tiempo después, los mapas de localizacionismo funcional en la corteza cerebral propuestos por John Hughlings-Jackson, Carl Wernicke y David Ferrier, finalizando con experiencias y casos cruciales para la modernidad, como el famoso caso de Phineas P. Gage.

Del capítulo diez al catorce se esboza el devenir histórico de las neurociencias en el siglo XX y su impacto sobre el desarrollo de la psiquiatría, neurología y psicología como disciplinas que, desde distintos niveles de análisis, pretenden explicar y/o intervenir el sistema nervioso central. Para ello se expone un entramado de contribuciones, como el desarrollo de la psicopatología de Emil Kraepelin, las experiencias con la histeria de Jean Martin Charcot y la definición de enfermedades claves del cerebro, como la resultante del trabajo de Alois Alzheimer, entre muchos otros. Luego se resumen los hallazgos que permitieron sentar las bases de la comprensión actual de los impulsos nerviosos y la transmisión neuroquímica. También se detallan contribuciones notables como los estudios de Wilder Penfield sobre la fisiología de las cortezas somatosensorial y motora primarias. Adicionalmente, se relatan experiencias claves en neurocirugía, como el caso del paciente $\mathrm{HM}$ en el estudio de la memoria. El capítulo catorce finaliza relatando hechos centrales en lo que respecta a la construcción de técnicas que hoy en día son angulares para el desarrollo de las neurociencias, como lo son la resonancia magnética funcional y algunas tecnologías desarrolladas en los últimos diez años, 
como las interfaces cerebro-computadora, entre otros contenidos.

Este libro nos permite revisar el desarrollo de las neurociencias en una línea de tiempo, configurando así una gran oportunidad para los estudiantes que desean una introducción comprensiva e histórica a las neurociencias, o para investigadores y clínicos que desean acceder, de manera ordenada y detallada, a los pasos que, a través de la historia, tuvo su propio quehacer actual.

Actualmente, este libro no se encuentra disponible en librerías chilenas, pero puede ser adquirido en librerías británicas. Entre las más recomendadas, se encuentra www.bookdepository. com, la cual no cobra gasto de envío a nuestro país. Adicionalmente, www.ebay.com y www. amazon.com, plataformas de compra y venta en línea, también venden este libro con envío a nuestro país.

Renzo C. Lanfranco, M.Sc. Departamento de Psiquiatría y Salud Mental, Facultad de Medicina, Universidad de Chile, Santiago, Chile. Laboratorio de Neurociencia Cognitiva y Social, UDP-Fundación INECO para las Neurociencias, Universidad Diego Portales, Santiago, Chile. 